\title{
Transient crustal deformation in Tokai region, central Japan, until May 2004
}

\author{
Shinzaburo Ozawa, Makoto Murakami, Masaru Kaidzu, and Yuki Hatanaka \\ Geography and Crustal Dynamics Research Center, Geographical Survey Institute of Japan, Kitasato-1, Tsukuba, Ibaraki 305-0811, Japan
}

(Received August 31, 2004; Revised August 6, 2005; Accepted August 7, 2005)

\begin{abstract}
An analysis of Global Positioning System (GPS) data reveals a continuation of the transient crustal deformation that was first reported by Ozawa et al. (2002) in the western Tokai region. Kalman filtering following the timedependent inversion shows a slow-thrust slip occurring on the plate boundary in the western Tokai region, with its center around Lake Hamana, which is adjacent to the anticipated Tokai earthquake source area. The moment release from the Tokai silent earthquake was observed to be continuous surpassing $M_{w} 7.0$ in May 2004, with relative slip increases to the northeast and north of Lake Hamana from 2002. The moment release rate decreased in 2002, and then increased in 2003, reaching the rate observed in 2001.
\end{abstract}

Key words: Tokai, transient crustal deformation, aseismic slip.

\section{Introduction}

The Tokai region is a well-known seismic gap located about $200 \mathrm{~km}$ southwest of Tokyo, where the Suruga trough, a subduction plate boundary between a continental plate and the Philippine sea plate, runs just offshore (see Fig. 1). Because of the subduction of the Philippine sea plate, the Tokai area has been struck by large offshore earthquakes at time intervals of approximately 150 years. The last Tokai earthquake, of M8.4, occurred in 1854 and released strain energy accumulated from the thrusting of the Philippine sea plate (Ando, 1975). Since then, the Tokai region has been accumulating strain energy from the loading of the Philippine sea plate; however, it failed to rupture during the 1944 Tonankai earthquake $\left(\mathrm{M}_{\mathrm{w}}=8.1\right)$ (Inouchi and Sato, 1975; Ishibashi, 1981; Mogi, 1981).

Historical geodetic survey data for the past 100 years and continuous GPS data, which have been recorded since 1994 by the Geographical Survey Institute of Japan (GSI), consistently indicate a steady strain accumulation in this region (Mogi, 1981; Sagiya, 1999). Based on these pieces of evidence, the Tokai region has been regarded as a seismic gap with the potential for an $M_{w} 8$ earthquake. The Japanese government enacted a law in 1978 to ensure adequate preparations for the expected Tokai earthquake, and many organizations working towards disaster prevention have established modern observation networks in the Tokai region.

Since the prediction of a future Tokai earthquake, many researchers have tried to estimate its asperity or focal area (Yoshioka et al., 1993; Matsumura, 1997; Sagiya, 1999; El-Fiky and Kato 2000). On the basis of these models, the Central Disaster Prevention Committee of the Japanese government adopted in 2001 the earthquake source area indicated in Fig. 1(b).

Ozawa et al. (2002) have reported the occurrence of a

Copyright (c) The Society of Geomagnetism and Earth, Planetary and Space Sciences (SGEPSS); The Seismological Society of Japan; The Volcanological Society of Japan; The Geodetic Society of Japan; The Japanese Society for Planetary Sciences; TERRAPUB. transient crustal deformation in the Tokai region that gradually became increasingly evident from the beginning of 2001 in the GPS time series. On the basis of the southeastward detrended movements of the GPS sites, they proposed the occurrence of a silent earthquake in the western Tokai region neighboring the estimated source area of the anticipated Tokai earthquake. This Tokai silent earthquake is continuing at present, with transient crustal motions at GPS sites reaching $5 \mathrm{~cm}$ horizontally and $4 \mathrm{~cm}$ vertically at maximum. This kind of silent earthquake, with a duration of more than three years to date, is unprecedented worldwide. At this stage, there is growing concern about the possibility that the Tokai region's transient crustal deformation will serve as a precursor leading to a catastrophic Tokai earthquake.

In this paper, we report on the current state of the ongoing Tokai transient crustal deformation on the basis of the latest GPS data.

\section{Global Positioning System Data}

The analytical procedure of the GPS array data (GPS Earth Observation Network; GEONET) of the GSI of Japan is described in detail by Hatanaka et al. (2003).

GPS 24 hour data are analyzed by means of Bernese GPS software (version 4.2) (Hugentobler et al., 2001), using the international GNSS service (IGS: igscb.jpl.nasa.gov) precise ephemeredes and Earth orientation parameters for the period between 1996 and 2004. Troposphere delays are estimated at each station for every three-hour period (Hatanaka et al., 2003). Since the GPS analysis results include annual and linear trend components, we eliminate these from the raw time series by fitting the following function to the raw time series for the period between 1997 and 1999, during which there were no transient crustal deformations.

$$
y=A t+B+\sum_{i=1}^{N}\left(C_{i} \sin \left(\frac{2 \pi t}{i T}\right)+D_{i} \cos \left(\frac{2 \pi t}{i T}\right)\right)
$$



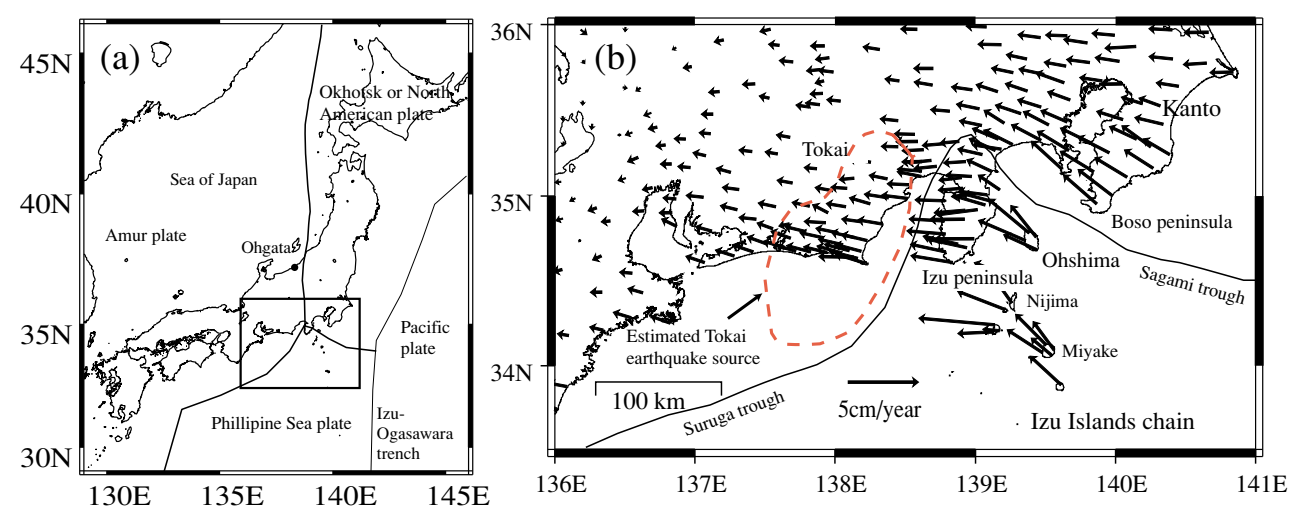

Fig. 1. (a) Tectonic settings in and around Japan. Solid lines indicate plate boundaries. (b) Magnified map of rectangular area in (a). The Philippine sea plate subducts beneath the continental plate from the Suruga and Sagami troughs. The black arrow represents the observed ground displacement rate in cm/year for the period between 1997 and 1999. Northwestward motions in the Kanto and Tokai regions are mainly due to the coupling effect between the subducting Philippine sea plate and the overriding continental plate. This crustal deformation is hereafter referred to as the steady state. Broken line represents the estimated source area of the expected Tokai earthquake.
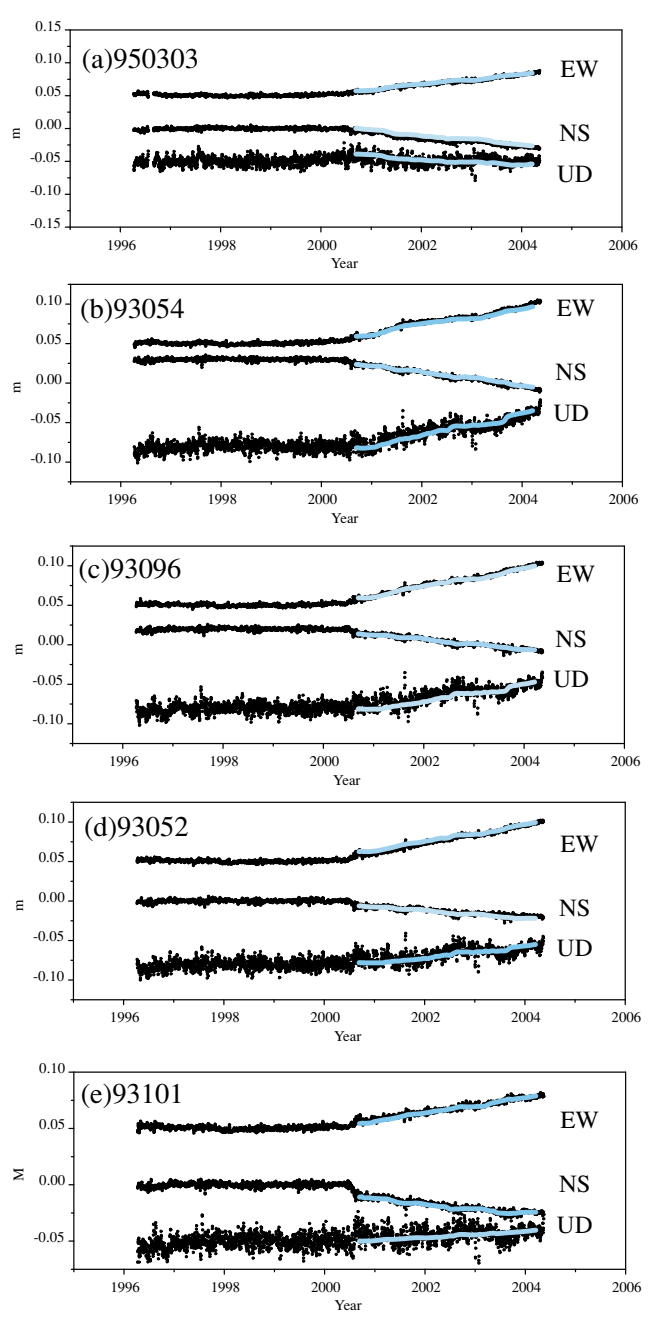

Fig. 2. Time series data of east-west (EW), north-south (NS), and up-down (UD) displacements at the selected GPS stations denoted by open circles in Fig. 3(a). The steady state crustal deformation shown in Fig. 1(b) and annual changes are removed. When ground displacement levels off in these figures, it indicates that ground motion is reduced to the steady-state deformation in Fig. 1(b). The Izu Island earthquakes mostly caused rate changes in the middle of 2000. Despite the subsidence of the 2000 Izu Island event, the selected stations show a clear deviation from 2001 onwards. The solid lines indicate the values calculated by Kalman filtering. (a) 303, (b) 054, (c) 096, (d) 052, (e) 101.
Here, $y$ and $t$ represent the observed crustal deformation data and time, respectively. $N$ is the degree of the trigonometric function, which is determined from AIC criteria (Akaike, 1974). $T$ is a period for annual components, being 1 year in this case. $A t+B$ in Eq. (1) is the linear component, while the remaining terms in Eq. (1) represent annual components. We assume that the estimated linear component represents a long-term interseismic deformation rate. We detrend the raw time series by removing the estimated linear and annual components from the data for the period between 1996 and 2004.

Figure 2 shows the detrended time series of data from selected GPS sites for the period between April 1996 and May 2004, with the annual and trend components removed. Transient motion in the middle of 2000 was caused by the 2000 Izu Island activity (Fig. 2) (Nishimura et al., 2001). After the $2000 \mathrm{Izu}$ Island event subsided, ground motion started to deviate from the beginning of 2001. Transient motion at site 93054 has exceeded $5 \mathrm{~cm}$ horizontally and $4 \mathrm{~cm}$ vertically since 2001 . Each station shows a different time evolution. As of May 2004, the Tokai transient motion is obviously still continuing.

The spatial pattern of the observed transient motion between January 2001 and January 2002 shows a southeastward movement of approximately $2 \mathrm{~cm}$ in the western Tokai region (Fig. 3(a)). This spatial pattern strongly suggests the possibility of an interplate slip between the Philippine sea plate and the overriding continental plate in this region, considering the steady northwestward motion observed between 1997 and 1999 (Fig. 1(b)). An upward motion of up to $2 \mathrm{~cm}$ is also observed east of Lake Hamana for the same period where maximum horizontal motions occur (Fig. 4(a)). The subsidence northwest of Lake Hamana and upheaval trend northeast from Lake Hamana hint aseismic slip area near Lake Hamana (Fig. 4(a)). Crustal deformation on the Izu Islands, as indicated in Fig. 3(a), indicates a continuation of the 2000 Izu Island event, although with lesser intensity than that during the peak period between July and August 2000. Southeastward displacements on the Izu Peninsula are partly attributed to the Izu Island activity, since a similar motion was observed during the 2000 

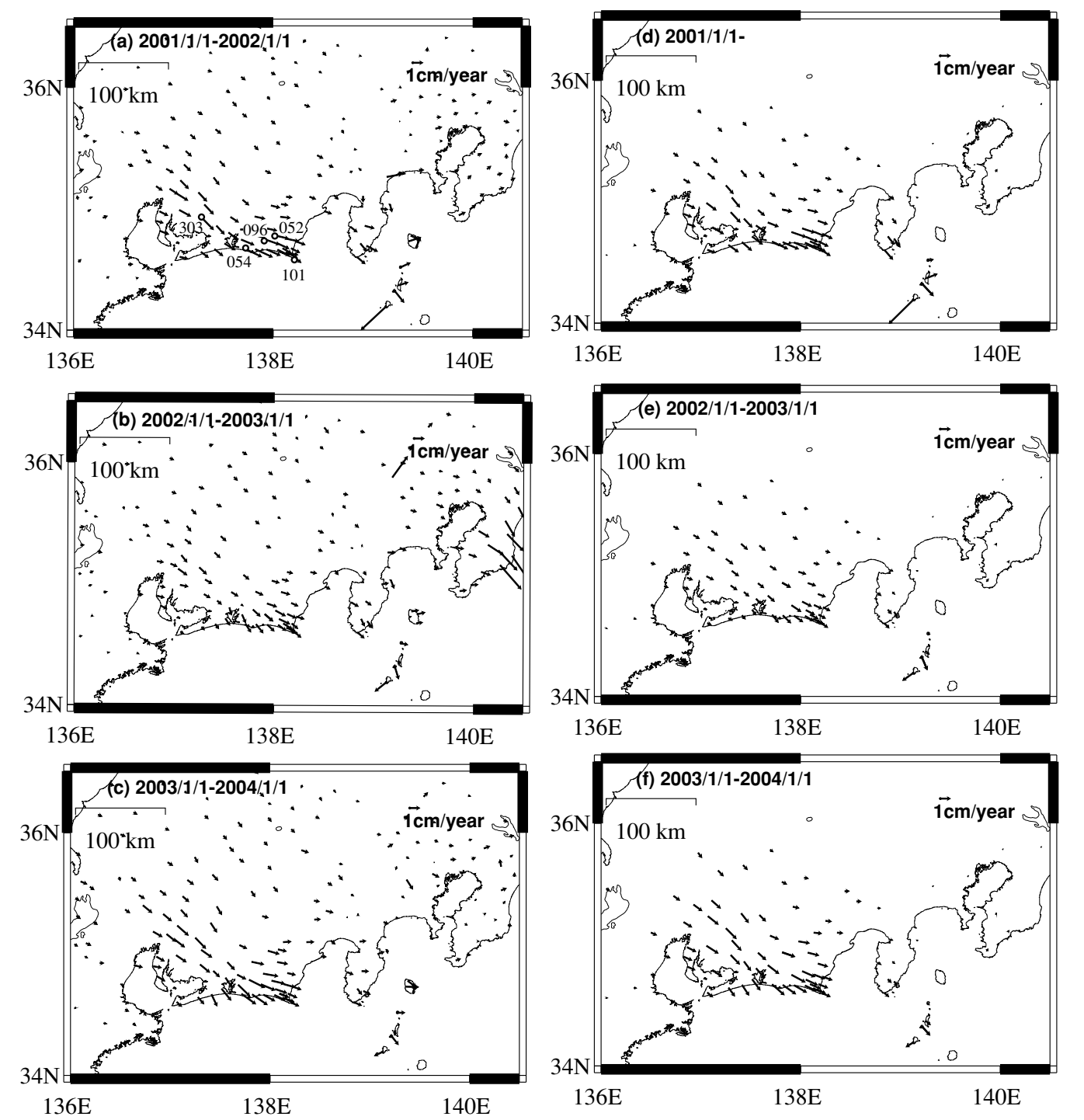

Fig. 3. (a) Solid arrows represent detrended crustal deformation or anomaly from the steady state shown in Fig. 1(b), for the period between January 2001 and January 2002. Southeastward motion in the Tokai region suggests the occurrence of a slow earthquake. The motion on the Izu peninsula is partly attributed to the Izu Island activity, whose effects are evidenced by the ground displacements on the Izu Islands. The open circles show the location of the selected GPS stations whose time series are shown in Fig. 2. (b) For period between January 2002 and January 2003 . Large displacements on the Boso peninsula were caused by aseismic interplate slip in 2002 off the coast of the Boso peninsula. (c) For period between January 2003 and January 2004. (d) Calculated crustal deformation for period between January 2001 and January 2002 using the model in Figs. 5 and 6. (e) Calculated crustal deformation for period between January 2002 and January 2003. (f) Calculated crustal deformation for period between January 2003 and January 2004.

Izu Island event (Nishimura et al., 2001). Compared with that shown in Fig. 3(a), the transient crustal deformation in 2002 is small in magnitude (Fig. 3(b)), suggesting the slowing down of interplate slip in the Tokai region. The upheaval area near Lake Hamana expanded to the north and northeast from 2001 to 2002 (Figs. 4(a) and 4(b)). However, in 2003, the magnitude of the Tokai transient crustal deformation increased again (Fig. 3(c)). The upheaval area near Lake Hamana has extended northeast over time and increased in magnitude from 2002 as shown in Fig. 4(c).

\section{Model Geometry and Kalman Filtering Analy- sis}

We assume that a silent earthquake is causing the transient crustal deformation in the Tokai region, as proposed by Ozawa et al. (2002). Under this assumption, we esti- mate the slip history between the Philippine sea plate and the overriding continental plate by square-root information filter (SRIF) (Bierman, 1977) following the time-dependent inversion technique (Segall and Matthews, 1997) using the data in Figs. 2-4, taking the 2000 Izu Island activity into account.

Figure 3(d) shows the GPS sites we used. Both horizontal and vertical displacement data are modeled at 99 selected GPS sites on the Izu Island chain, and in the Kanto and Tokai regions of Japan.

First, we determined the model geometry of the Tokai silent earthquake and the Izu Island earthquake, which are still affecting the Tokai transient motion. With regard to the Tokai plate boundary model, we used the plate boundary estimated by Ishida (1992). We adopted the 2000 Izu Island model estimated in this study, which is shown in 

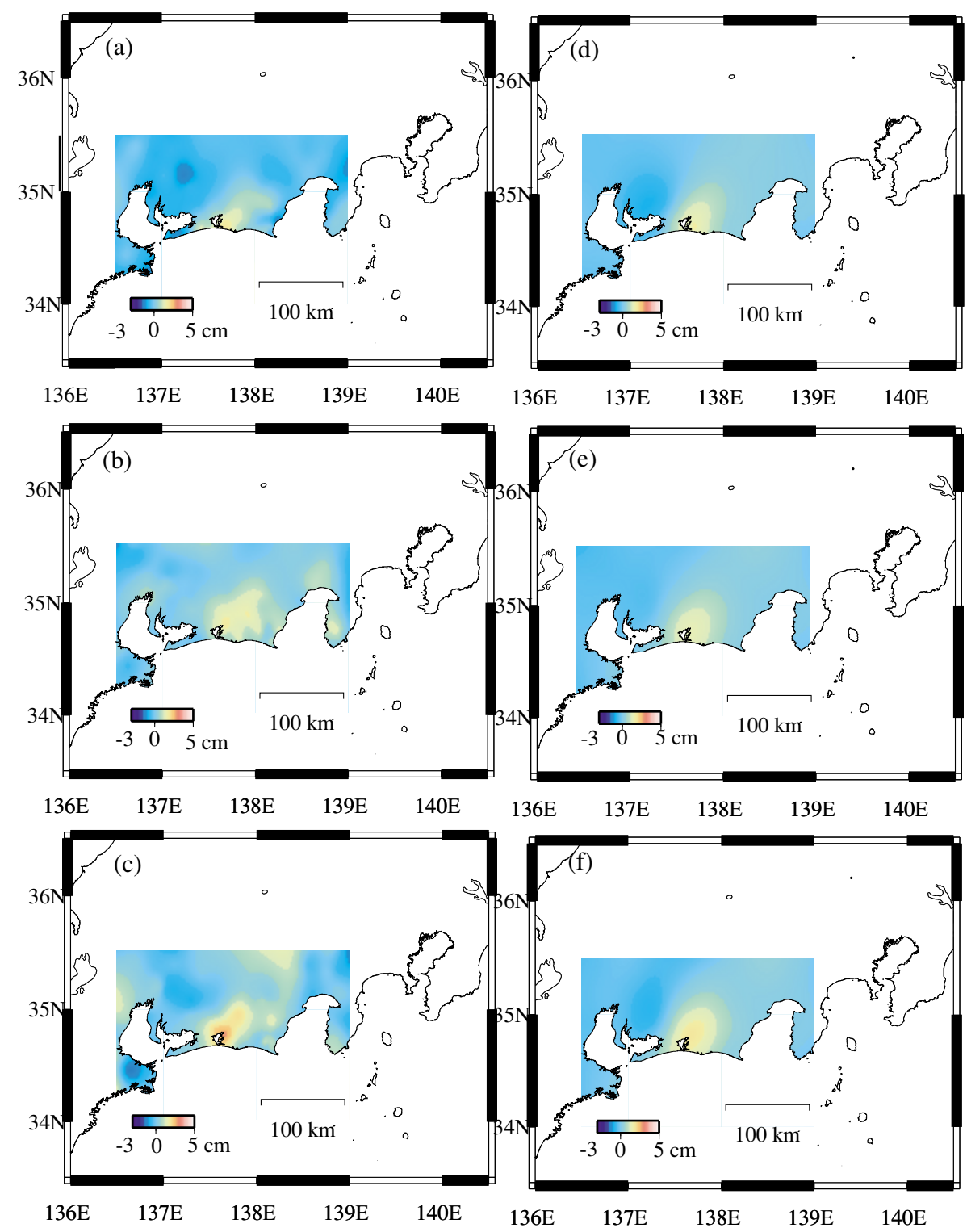

Fig. 4. (a) Vertical crustal deformation for period between January 2001 and January 2002. Color contours represent the magnitude of vertical motion. (b) For period between January 2002 and January 2003. (c) For period between January 2003 and January 2004. (d) Calculated vertical deformation for period between January 2001 and January 2002. (e) Calculated vertical deformation for period between January 2002 and January 2003. (f) Calculated vertical deformation for period between January 2003 and January 2004.

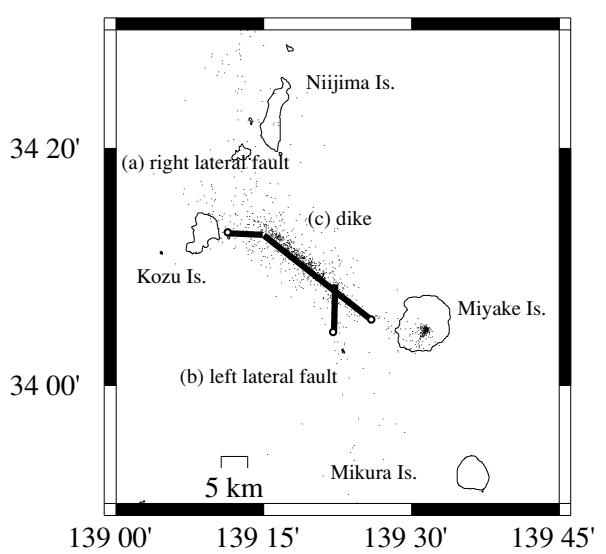

Fig. 5. The adopted Izu Island model. (a) Right-lateral creeping fault. (b) Left-lateral creeping fault. (c) Dike. Open circles show the locations whose longitude, latitude, and depth are summarized in Table 1.
Fig. 5 and Table 1. The fault parameters of normal character in Table 1 were estimated by linearized least-squares fitting, using Okada's formula (Okada, 1985). After representing the above model region by spline surface (Ozawa $e t$ al., 2001), we estimated the slip history between September 2000 and May 2004 using a square-root information filter (SRIF) (Bierman, 1977) on the basis of the time-dependent inversion technique. We set the slip components at zero at the edge of the fault patch as a boundary condition. Furthermore, we adopted the condition that the slip motion is southward and eastward for the Tokai silent slip and the rake angle is within $\pm 45^{\circ}$ for the right-lateral and left-lateral faults, with unidirectional motion over time for all the components, including dike opening. We introduced these nonnegativity or inequality constraints by adopting the hardconstraint method presented by Simon and Simon (2003). 


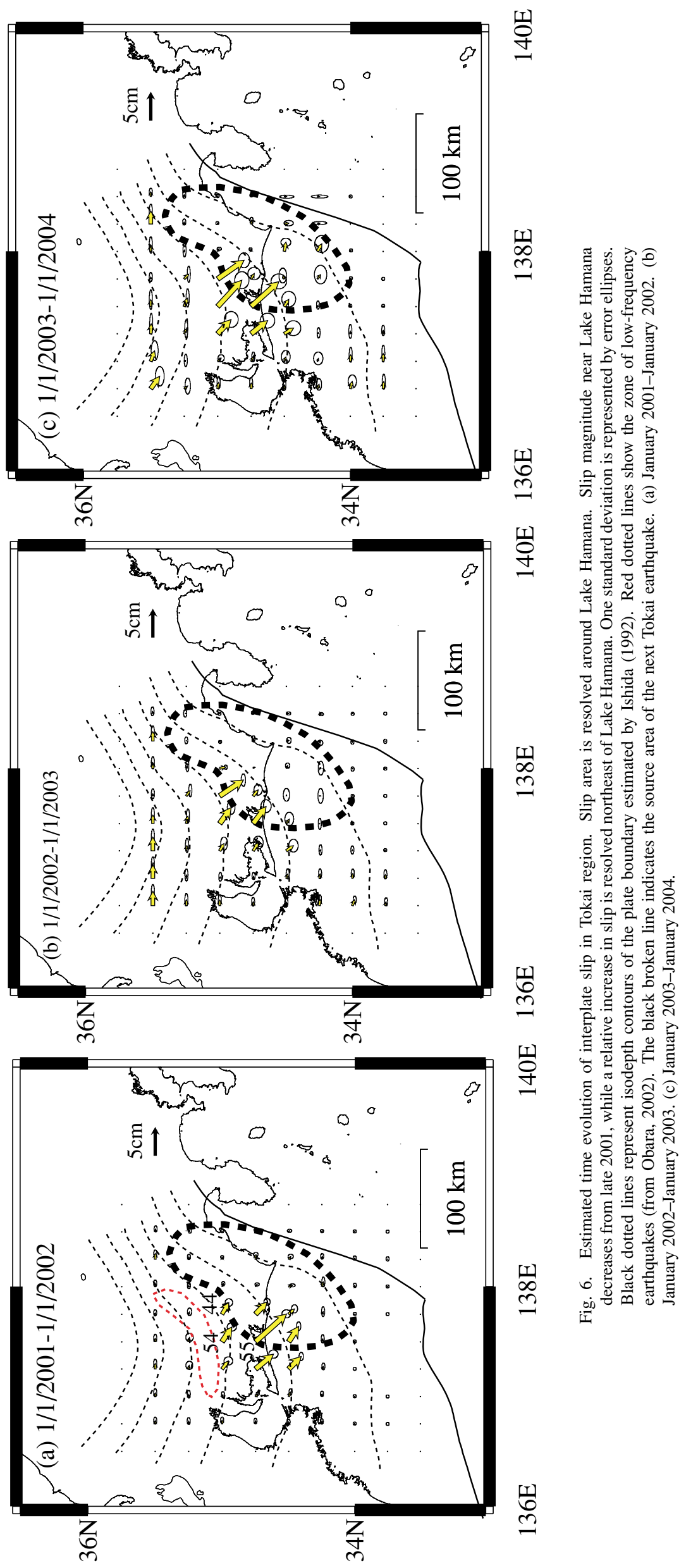


Table 1. Adopted rectangular fault parameters for 2000 Izu Island model. Lat, Long, and Depth, respectively, represent latitude, longitude, and depth at the lower right corner of a rectangular fault denoted by open circles in Fig. 5. Parameters of normal character are estimated by the linearized least-squares method. We enlarge these rectangular faults along the strike and dip directions and use a spline surface to represent the enlarged ones.

\begin{tabular}{lccccccc}
\hline No. & Lat $\left({ }^{\circ} \mathrm{N}\right)$ & Long $\left({ }^{\circ} \mathrm{E}\right)$ & Depth $(\mathrm{km})$ & Strike $(\mathrm{km})$ & Dip $\left({ }^{\circ}\right)$ & Width $(\mathrm{km})$ & Length $(\mathrm{km})$ \\
\hline a. right lateral & 34.216 & 139.137 & 30 & 173 & 90 & 30 & 8 \\
b. left lateral & 34.104 & 139.377 & 30 & 182 & 91 & 30 & 8 \\
c. dike & 34.125 & 139.40 & 30 & 309 & 88 & 30 & 15 \\
\hline
\end{tabular}
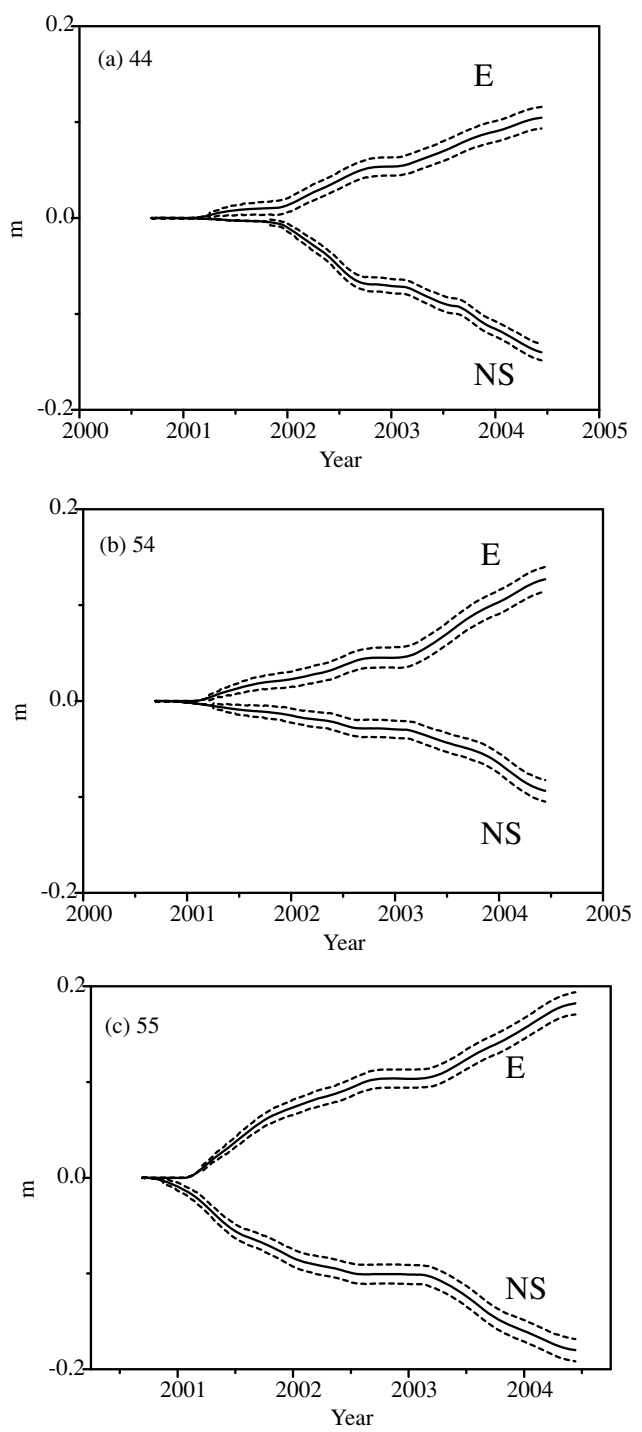

Fig. 7. Estimated slip history at selected points on plate interface in Tokai region, Japan. The location of the selected points is shown in Fig. 6(a). EW and NS represent east-west and north-south slips with east and north positive. 3 standard deviation is shown by broken lines. (a) 44, (b) 54 , and (c) 55 .

\section{Results and Discussion}

Figure 6 shows the result for the Tokai silent earthquake. Error ellipsoids represent one standard deviation error in the estimated slip. The aseismic slip area is estimated to be around Lake Hamana in the western Tokai region close to the estimated Tokai source area in 2001 (Fig. 6(a)). A lowfrequency-earthquake area (Obara, 2002) is north of the slip area in Fig. 6(a). This slip pattern produces southeastward horizontal displacements and vertical motion on the surface that well match the observations (see Figs. 3 and 4).
Between January 2002 and January 2003, the estimated slip magnitude decreased near Lake Hamana and a relative slip increase was observed northeast of Lake Hamana (Fig. 6(b)). This change in the slip area is beyond the standard deviation error. From January 2003 to January 2004, the estimated slip increased in magnitude compared with that in 2002 (Fig. 6(b)), while the slip area shifted northward. Figure 7 shows the slip history of selected points on the fault patch (see Fig. 6(a)). Point 55 started moving in the late 2001, while points 44 and 54 were delayed in their start of movement. In particular, point 54 increased its slip rate during 2003. These features did not extensively change within three times standard deviation error. Figure 8 shows the time evolution of a moment release from the estimated Tokai interplate slip. As shown in this figure, the moment release from the Tokai silent slip started in the late 2000, and increased linearly up to July 2001. From July 2001, the moment release rate remained roughly the same and decreased in the late 2002, and increased between 2003 and 2004. These characteristic points showed minimal change within three times standard deviation error.

Figures 2, 3(d)-(f), and 4(d)-(f) show computed ground displacements from the estimated slip model in Figs. 6 and 7 , and there is a good degree of consistency between the observed and computed values within the standard deviation error of observations, which is about $2 \mathrm{~mm}$ horizontally and $6 \mathrm{~mm}$ vertically. In summary, our analysis resolved the space-time distribution of the silent slip in the Tokai region that has been occurring since 2001, which is centered on Lake Hamana close to the seismic gap. Previous studies of silent earthquakes suggest that silent slips tend to occur in weakly coupled regions (e.g., Hirose et al., 2000). The area at the boundary of the estimated source of the expected Tokai earthquake matches this criterion and is consistent with previous studies of silent earthquakes. However, the duration of more than three years is much longer than other aseismic slip events that have occurred in Japan since 1994, when the permanent GPS network started operation (e.g., Hirose et al., 1999; Sagiya, 2004).

Obara (2002) discovered nonvolcanic low-frequency tremors which were distributed along the strike of the subducting Philippine sea plate in Japan, suggesting a relationship of tremors and the subduction. Rogers and Dragert (2003) have pointed out the association of low-frequency earthquakes with the Cascadia aseismic event. Hirose and Obara (2003) and Obara and Hirose (2003) also discovered a tilt meter change associated with the occurrence of lowfrequency earthquakes in the area near the Bungo channel, in southwest Japan. With regard to the Tokai silent event, there exists a low-frequency earthquake zone nearby (see Fig. 6(a)). However, the relationship between the low- 


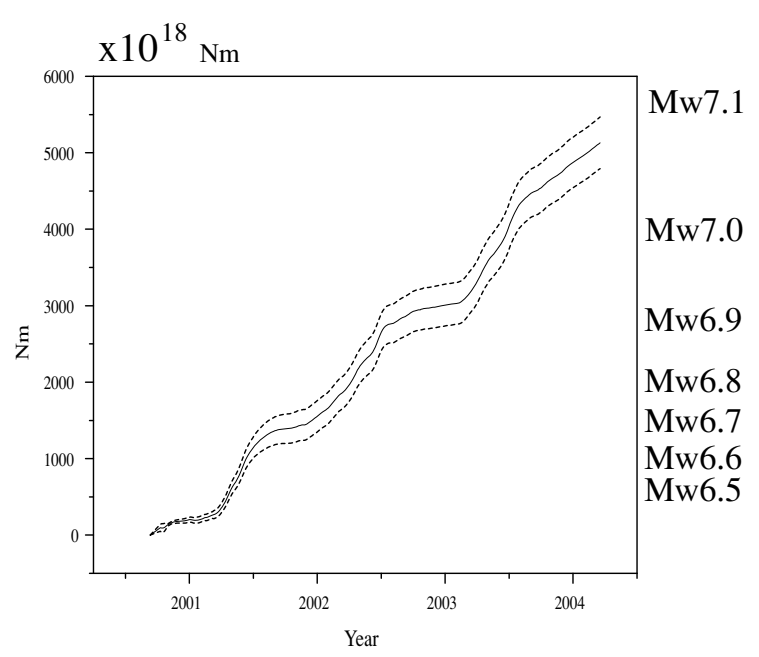

Fig. 8. Estimated time evolution of cumulative moment release of interplate slip in Tokai region, Japan. Broken lines represent 3 standard deviation error. Moment release rate slightly decreased in the late 2002 and increased again from 2003 to 2004.

frequency earthquakes and the aseismic slip in the Tokai region has not yet been clarified. Some researchers have claimed that low-frequency earthquakes become frequent when aseismic slip rate increases in the Tokai region (Ishigaki et al., 2004), while others have suggested a more obscure relationship between them (Obara and Hirose, 2004).

Kimata has reexamined past electric distance measurements and suggested the possibility of at least two similar silent events near the area of the estimated silent event of 2001 (Kimata et al., 2003) during the periods 1978-1983 and 1987-1991. Hashimoto (2003) has also pointed out transient strain changes in the 1980 s, as revealed by trilateration.

Although the past two silent earthquakes did not lead to a catastrophic earthquake in the Tokai region, we do not know what factors keep silent earthquakes from becoming catastrophic ruptures, or whether the present silent event will eventually subside or lead to a catastrophic event. Thus, an intensive monitoring of the temporal evolution of this phenomenon and timely updates of a physical model of the Tokai slow event are necessary.

Acknowledgments. We are grateful to Dr. Miyazaki of the Earthquake Research Institute, University of Tokyo, for helpful discussion.

\section{References}

Akaike, H., A new look at the statistical model identification, IEEE, Trans. Auto. Control, AC-19, 716-723, 1974.

Ando, M., Source mechanism and tectonic significance of historical earthquakes along the Nankai trough, Japan, Tectonophysics, 27, 119-140, 1975.

Bierman, G. J., Factorization Methods for Discrete Sequential Estimation, Academic Press, New York, 1977.

El-Fiky, G. and T. Kato, Study of periodic vertical movement in the Omaezaki peninsula, central Japan, and its tectonic implications, Earth Planets Space, 52, 25-35, 2000.

Hashimoto, M., Abnormal strain change in the Tokai region in the 1980's, Chikyu Monthly, 41, 20-26, 2003.

Hatanaka, Y. et al., Improvement of the analysis strategy of GEONET, Bull. Geograph. Survey Inst., 49, 11-37, 2003.

Hirose, H. and K. Obara, Repeating slow slip events which correlated deep low-frequency tremor activity in southwest Japan, Fall Meeting of Seismological Society of Japan, 2003.

Hirose, H., K. Hirahara, F. Kimata, N. Fujii, and S. Miyazaki, A slow thrust slip event following the 1996 Hyuga-nada earthquakes beneath the Bungo Channel, southwest Japan, Geophys. Res. Lett, 26, 3237$3240,1999$.

Hirose, I., I. Kawasaki, Y. Okada, T. Sagiya, and Y. Tamura, A silent earthquake of December 9, 1989, in the Tokyo Bay, as revealed by the continuous observation of crustal movements in the southern Kanto district, central Japan, J. Seismol. Soc. Jpn., 53, 11-23, 2000 (in Japanese with English abstract).

Hugentobler, U., S. S. Shaer, and P. Fridez (eds.), The BERNESE GPS software Version 4.2, Astronomical Institute, University of Berne, 515 pp., 2001.

Inouchi, N. and H. Sato, Vertical crustal deformation accompanied with the Tonankai Earthquake of 1944, Bull. Geogr. Survey Inst. Japan, 21, 10-18, 1975.

Ishibashi, K., Identification of a soon-to-occur seismic faulting in the Tokai district, central Japan, based upon seismotectonics, in Earthquake Prediction, Maurice Ewing Series, IV, pp. 297-332, AGU, Washington D.C., 1981.

Ishida, M., Geometry and relative motion of the Philippine sea plate and Pacific plate beneath the Kanto-Tokai district, Japan, J. Geophys. Res., 97, 489-513, 1992.

Ishigaki et al., Synchronization between aseismic slip in the Tokai district and low-frequency earthquakes, Spring meeting of the Seismological Society of Japan, 2004.

Kimata, F., K. Hirahara, and N. Fujii, Repeated slow slip events and the occurrence process of the large earthquakes in the Tokai region, central Japan, 2003 IUGG Meeting, JSS01/30A/D-040, 2003.

Matsumura, S., Focal zone of a future Tokai earthquake inferred from the seismicity pattern around the plate interface, Tectonophysics, 273, 271291, 1997.

McGuire J. J. and P. Segall, Imaging of aseismic fault slip transients recorded by dense geodetic networks, Geophy. J. Int., 155, 778-788, 2003.

Mogi, K., Earthquake prediction program in Japan, in Earthquake Prediction, An International Review, Maurice Ewing Series, IV, pp. 635-666, AGU, Washington D.C., 1981.

Nishimura, T. et al., Crustal deformation caused by magma migration in the northern Izu Islands, Japan, Geophy. Res. Lett., 28, 3745-3748, 2001.

Obara, K., Nonvolcanic deep tremor associated with subduction in southwest Japan, Science, 296, 1679-1681, 2002.

Obara, K. and H. Hirose, Periodic activity of deep low-frequency earthquakes and correlated tilt changes observed in southwest Japan subduction zone, Fall Meeting of Seismological Society of Japan, 2003.

Obara, K. and H. Hirose, Deep low-frequency tremors and slow slip events, Rep. Coord, Commit, Eq. Pred., 72, 575-581, 2004.

Okada, Y., Surface deformation due to shear and tensile faults in halfspace, Bull. Seism. Soc. Am., 75, 1135-1154, 1985.

Ozawa, S., M. Murakami, and T. Tada, Time-dependent inversion analysis of the slow thrust event in the Nankai trough subduction zone, southwestern Japan, J. Geophys. Res., 106, 787-802, 2001.

Ozawa, et al., Detection and Monitoring of ongoing aseismic slip in the Tokai region, central Japan, Science, 298, 1009-1012, 2002.

Rogers, G. and H. Dragert, Episodic tremor and slip on the Cascadia subduction zone: the chatter of silent slip, Science, 300, 1942-1943, 2003.

Sagiya, T., Interplate coupling in the Tokai district, central Japan, deduced from continuous GPS data, Geophys. Res. Lett., 26, 2315-2318, 1999.

Sagiya, T., Interplate coupling in the Kanto District, central Japan, and the Boso Silent earthquake in May 1996, PAGEOPH, 2004 (in press).

Segall, P. and M. Matthews, Time-dependent inversion of geodetic data, $J$. Geophys. Res., 102, 22391-22409, 1997.

Simon, D. and D. L. Simon, Aircraft turbofan engine health estimation using constrained Kalman filtering, ASME Turbo Expo 2003, Atlanta, GA, paper GT2003-38584, 2003.

Yoshioka, et al., Interplate coupling and relative plate motion in the Tokai district, central Japan, deduced from geodetic inversion using ABIC, Geophys. J. Int., 113, 607-621, 1993.

S. Ozawa (e-mail: ozawa@gsi.go.jp), M. Murakami (e-mail: mccopy@gsi.go.jp), M. Kaidzu (e-mail: kaidzu@gsi.go.jp), and Y. Hatanaka (e-mail: hata@gsi.go.jp ) 